Pacific Journal of Mathematic 


\title{
ON THE CONVERGENCE OF A TRIGONOMETRIC INTEGRAL
}

\author{
R. Mohanty AND B. K. Ray
}

In the present paper, we shall first establish a theorem concerning the convergence of a trigonometric integral. Then in the final section, we shall evaluate some known definite integrals with the help of our theorem.

1. Definition. We say that the integral $\int_{0}^{\infty} a(u) d u$ is summable $(C, 1)$ to sum $S$, if

$$
\lim _{\lambda \rightarrow \infty} \int_{0}^{\lambda}\left(1-\frac{u}{\lambda}\right) a(u) d u=S
$$

In [1], a result regarding the $(C, 1)$ summability of a trigonometric integral was proved which is equivalent to

Theorem $A$. Let $f(t)$ be $L$ over $(0, \infty)$. Then, for $0<\alpha<1$, the integral

$$
\int_{0}^{\infty} u^{\alpha} d u \int_{0}^{\infty} f(t) \sin u t d t
$$

is summable $(C, 1)$ to

$$
\Gamma(\alpha+1) \operatorname{Cos} \frac{1}{2} \alpha \pi \int_{\rightarrow 0}^{\infty} \frac{f(t)}{t^{1+\alpha}} d t
$$

whenever this integral exists and whenever

$$
f(t)=0\left(t^{\alpha}\right) \text { as } \quad t \rightarrow 0 .
$$

In $\S 2$ of the present paper we establish the following theorem.

THEOREM. Let $t^{-\alpha} f(t)(0<\alpha<1)$ be of bounded variation over $(0, \infty)$ and tend to zero both as $t \rightarrow 0$ and $t \rightarrow \infty$. If the integral $\int_{0}^{+\infty} f(t) \sin u t d t$ is uniformly convergent with respect to $u$ over $0<$ $\mu \leqq u \leqq \lambda<\infty$, for every $\mu$ and $\lambda$, then

$$
\int_{\rightarrow 0}^{\rightarrow \infty} u^{\alpha} d u \int_{0}^{\rightarrow \infty} f(t) \sin u t d t=\Gamma(\alpha+1) \cos \frac{1}{2} \alpha \pi \int_{\rightarrow 0}^{\rightarrow \infty} \frac{f(t)}{t^{1+\alpha}} d t
$$

whenever the last integral exists.

In the present problem $f(t)$ is not necessarily $L$ over $(0, \infty)$. In 
$\S 3$ we shall evaluate some known definite integrals with the help of the above theorem.

2. For the proof of the theorem, we use the following simple lemma.

LEMma. If the function $g(t)$ is positive and nonincreasing over the interval $(a, \infty)$, then

$$
\left|\int_{a}^{\rightarrow \infty} g(t) \cos t d t\right| \leqq A g(a) \cdot \cdot^{1}
$$

Proof of the theorem. We write $h(t)=t^{-\alpha} f(t)$. For any $\varepsilon>0$, there is a $\delta$ such that $|h(t)|<\varepsilon$ for all $t<\delta$ and for all $t>1 / \delta$. For the sake of simplicity, we shall drop the sign $\rightarrow$ at infinity in the proof. We have

$$
\int_{\mu}^{\lambda} u^{\alpha} d u \int_{0}^{\infty} f(t) \sin u t d t=\int_{0}^{\infty} f(t) d t \int_{\mu}^{\lambda} u^{\alpha} \sin u t d u
$$

since the inversion of order of integration is justified by the uniform convergence of the inner integral of the left side of (2.1). Using integration by parts, we get

$$
\int_{\mu}^{\lambda} u^{\alpha} \sin u t d u=\frac{\mu^{\alpha}}{t} \cos \mu t-\frac{\lambda^{\alpha}}{t} \cos \lambda t-\frac{\alpha}{t^{\alpha+1}} \int_{\mu t}^{\lambda t} \frac{\cos u}{u^{1-\alpha}} d u,
$$

and then the equation (2.1) becomes

$$
\begin{aligned}
& \int_{\mu}^{\lambda} u^{\alpha} d u \int_{0}^{\infty} f(t) \sin u t d t \\
& \quad=\mu^{\alpha} \int_{0}^{\infty} \frac{h(t)}{t^{1-\alpha}} \cos \mu t d t-\lambda^{\alpha} \int_{0}^{\infty} \frac{h(t)}{t^{1-\alpha}} \cos \lambda t d t+\alpha \int_{0}^{\infty} \frac{h(t)}{t} d t \int_{\mu t}^{\lambda t} \frac{\cos u}{u^{1-\alpha}} d u \\
& \quad=I-J+K .
\end{aligned}
$$

Now

$$
\begin{aligned}
|I| & =\mu^{\alpha}\left|\int_{0}^{\varepsilon / \mu}+\int_{\varepsilon / \mu}^{\infty}\right| \\
& \leqq A \mu^{\alpha} \int_{0}^{\varepsilon / \mu} \frac{d t}{t^{1-\alpha}}+\left|\int_{\varepsilon}^{\infty} \frac{h(v / \mu)}{v^{1-\alpha}} \cos v d v\right| \\
& \leqq A \varepsilon^{\alpha}+o(1) \text { as } \mu \rightarrow 0,
\end{aligned}
$$

by applying the lemma for the last integral, after writing $h(t)$ as the difference of two functions which tend to zero monotonically. Similarly

1 Throughout the present paper we write $A$ for an arbitrary constant which is not necessarily the same at each occurrence. 


$$
\begin{aligned}
|J| & =\lambda^{\alpha}\left|\int_{0}^{1 / \lambda}+\int_{1 / \lambda}^{1 / \varepsilon \lambda}+\int_{1 / \varepsilon \lambda}^{\infty}\right| \\
& \leqq o(1) \lambda^{\alpha} \int_{0}^{1 / \lambda} \frac{d t}{t^{1-\alpha}}+A \int_{1}^{1 / \epsilon}|h(v / \lambda)| d v+\left|\int_{1 / \varepsilon}^{\infty} \frac{h(v / \lambda)}{v^{1-\alpha}} \cos v d v\right| \\
& \leqq A \varepsilon^{1-\alpha}+o(1) \text { as } \lambda \rightarrow \infty .
\end{aligned}
$$

Thus it is sufficient to prove that

$$
\limsup _{\lambda \rightarrow \infty, \mu \rightarrow 0}\left|k-\alpha \int_{1 / \lambda}^{\infty} \frac{h(t)}{t} d t \int_{0}^{\infty} \frac{\cos u}{u^{1-\alpha}} d u\right| \leqq A \varepsilon^{\alpha},
$$

since

$$
\int_{0}^{\infty} u^{\alpha-1} \cos u d u=\Gamma(\alpha) \cos \frac{1}{2} \alpha \pi .
$$

The term inside the absolute value sign of (2.2) is

$$
\begin{aligned}
k-\alpha \int_{1 / \lambda}^{\infty} \frac{h(t)}{t} d t \int_{0}^{\infty} \frac{\cos u}{u^{1-\alpha}} d u= & \alpha \int_{0}^{1 / \lambda} \frac{h(t)}{t} d t \int_{\mu t}^{\lambda t} \frac{\cos u}{u^{1-\alpha}} d u \\
& -\alpha \int_{1 / \lambda}^{\infty} \frac{h(t)}{t} d t \int_{0}^{\mu t} \frac{\cos u}{u^{1-\alpha}} d u \\
& -\alpha \int_{1 / \lambda}^{\infty} \frac{h(t)}{t} d t \int_{\lambda t}^{\infty} \frac{\cos u}{u^{1-\alpha}} d u \\
= & \alpha(L-M-N) .
\end{aligned}
$$

Now,

$$
\begin{aligned}
|L| & \leqq \int_{0}^{1 / \lambda} \frac{|h(t)|}{t^{1}} d t \int_{0}^{\lambda t} \frac{d u}{u^{1-\alpha}} \\
& \leqq A \lambda^{\alpha} \int_{0}^{1 / \lambda} \frac{|h(t)|}{t^{1-\alpha}} d t=o(1) \quad \text { as } \quad \lambda \rightarrow
\end{aligned}
$$

By the formula

$$
\int_{0}^{t} \frac{\cos \mu v}{v^{1-\alpha}} d v=\frac{\sin \mu t}{\mu t^{1-\alpha}}+\frac{1-\alpha}{\mu} \int_{0}^{t} \frac{\sin \mu v}{v^{2-\alpha}} d v,
$$

we get

$$
\begin{aligned}
M & =\mu^{\alpha} \int_{1 / \lambda}^{\infty} \frac{h(t)}{t} d t \int_{0}^{t} \frac{\cos \mu v}{v^{1-\alpha}} d v \\
& =\frac{1}{\mu^{1-\alpha}} \int_{1 / \lambda}^{\infty} \frac{h(t) \sin \mu t}{t^{2-\alpha}} d t+\frac{1-\alpha}{\mu^{1-\alpha}} \int_{1 / \lambda}^{\infty} \frac{h(t)}{t} d t \int_{0}^{t} \frac{\sin \mu v}{v^{2-\alpha}} d v \\
& =M_{1}+M_{2}
\end{aligned}
$$

where 


$$
\begin{aligned}
\left|M_{1}\right| & =\left|\int_{\mu / \lambda}^{\infty} \frac{h(v / \mu) \sin v}{v^{2-\alpha}} d v\right| \\
& \leqq\left|\int_{\mu / \lambda}^{\epsilon}\right|+\left|\int_{\varepsilon}^{\infty}\right| \leqq A \varepsilon^{\alpha}+o(1) \text { as } \mu \rightarrow 0
\end{aligned}
$$

and

$$
\begin{aligned}
M_{2}= & \frac{A}{\mu^{1-\alpha}} \int_{1 / \lambda}^{\infty} \frac{h(t)}{t} d t \int_{0}^{1 / \lambda} \frac{\sin \mu v}{v^{2-\alpha}} d v \\
& +\frac{A}{\mu^{1-\alpha}} \int_{1 / \lambda}^{\infty} \frac{\sin \mu v}{v^{2-\alpha}} d v \int_{v}^{\infty} \frac{h(t)}{t} d t \\
= & o(1)+A \int_{\mu / \lambda}^{\infty} \frac{\sin \omega}{\omega^{2-\alpha}} d \omega \int_{\omega / \mu}^{\infty} \frac{h(t)}{t} d t
\end{aligned}
$$

where the change of order of integration is easily proved, and then

$$
\left|M_{2}\right| \leqq A \varepsilon^{\alpha}+o(1)
$$

Finally

$$
\begin{aligned}
|N| \leqq & \frac{A}{\lambda^{1-\alpha}} \int_{1 / \lambda}^{\delta} \frac{|h(t)|}{t^{2-\alpha}} d t+\int_{\delta}^{1 / \delta} \frac{|h(t)|}{t} d t \int_{\lambda t}^{\infty} \frac{\cos v}{v^{1-\alpha}} d v \\
& +\frac{A}{\lambda^{1-\alpha}} \int_{1 / \delta}^{\infty} \frac{|h(t)|}{t^{2-\alpha}} d t \\
\leqq & A \varepsilon+o(1) \text { as } \lambda \rightarrow \infty .
\end{aligned}
$$

Thus we get the required inequality (2.2) and the theorem is completely proved.

3. Evaluation of integrals. Let us consider the function

$$
f(t)=t /\left(1+t^{2}\right) \quad(0, \infty) \text {. }
$$

Then the integral of the left side of (1.1) for the present function reduces to

$$
\begin{aligned}
& \int_{0}^{\infty} u^{\alpha} d u \int_{0}^{\infty} \frac{t}{1+t^{2}} \sin u t d t \\
& \quad=\frac{\pi}{2} \int_{0}^{\infty} u^{\alpha} e^{-u} d u=\frac{\pi}{2} \Gamma(\alpha+1) .
\end{aligned}
$$

Obviously, the function satisfies all the conditions of the theorem, so we have

$$
\frac{\pi}{2} \Gamma(\alpha+1)=\Gamma(\alpha+1) \cos \frac{1}{2} \alpha \pi \int_{0}^{\infty} \frac{t^{-\alpha}}{1+t^{2}} d t
$$

i.e., 


$$
\int_{0}^{\infty} \frac{t^{-\alpha}}{1+t^{2}} d t=\frac{\pi}{2 \cos \frac{1}{2} \alpha \pi} \text { for } 0<\alpha<1 .
$$

Next we consider the function

$$
f(t)=t^{3} /\left(1+t^{4}\right) \quad(0, \infty) .
$$

Obviously, this function satisfies the hypotheses of the theorem of the present paper. The integral on the left side of (1.1) for the present function reduces to

$$
\begin{aligned}
& \int_{0}^{\infty} u^{\alpha} d u \int_{0}^{\infty} \frac{t^{3}}{1+t^{4}} \sin u t d t \\
& \quad=\frac{\pi}{2} \int_{0}^{\infty} u^{\alpha} e^{-u / \sqrt{2}} \cos \frac{u}{\sqrt{2}} d u=\frac{\pi}{2} \Gamma(\alpha+1) \cos (\alpha+1) \frac{\pi}{4} .
\end{aligned}
$$

Now by the theorem of the present note, we have

$$
\frac{\pi}{2} \Gamma(\alpha+1) \cos (\alpha+1) \frac{\pi}{4}=\Gamma(\alpha+1) \cos \frac{1}{2} \alpha \pi \int_{0}^{\infty} \frac{t^{2-\alpha}}{1+t^{4}} d t .
$$

Therefore

$$
\int_{0}^{\infty} \frac{t^{2-\alpha}}{1+t^{4}} d t=\frac{\pi}{2} \frac{\cos (\alpha+1) \pi / 4}{\cos \frac{1}{2} \alpha \pi} \text { for } 0<\alpha<1 .
$$

Finally, we would like to express our indebtedness to the referee who suggested some improvements both in the hypotheses and the proof of the theorem as presented in the original manuscript. The second author is thankful to the University Grants Commission, New Delhi, for financial support.

\section{REFERENCE}

1. R. Mohanty, Evaluation of a trigonometric integral, Proc. Amer. Math. Soc. 8 (1957), 107-110.

Received April 1, 1969.

RAVENSHAW COLLEGE

CUTTACK-3, (ORISSA), INDIA

Government Science College

Phulbani (ORISSa), India 



\title{
PACIFIC JOURNAL OF MATHEMATICS
}

\author{
EDITORS
}

H. SAMELSON

Stanford University

Stanford, California 94305

J. DugunduI

Department of Mathematics

University of Southern California

Los Angeles, California 90007

RICHARD PIERCE

University of Washington

BASIL GORDON*

University of California

Seattle, Washington 98105

Los Angeles, California 90024

\section{ASSOCIATE EDITORS}

E. F. BeCKenbaCh

B. H. NeumanN

F. WOLF

K. YosHIDA

\section{SUPPORTING INSTITUTIONS}

\author{
UNIVERSITY OF BRITISH COLUMBIA \\ CALIFORNIA INSTITUTE OF TECHNOLOGY \\ UNIVERSITY OF CALIFORNIA \\ MONTANA STATE UNIVERSITY \\ UNIVERSITY OF NEVADA \\ NEW MEXICO STATE UNIVERSITY \\ OREGON STATE UNIVERSITY \\ UNIVERSITY OF OREGON \\ OSAKA UNIVERSITY \\ UNIVERSITY OF SOUTHERN CALIFORNIA
}

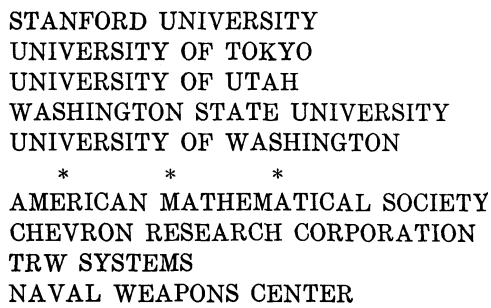

The Supporting Institutions listed above contribute to the cost of publication of this Journal, but they are not owners or publishers and have no responsibility for its content or policies.

Mathematical papers intended for publication in the Pacific Journal of Mathematics should be in typed form or offset-reproduced, double spaced with large margins. Underline Greek letters in red, German in green, and script in blue. The first paragraph or two must be capable of being used separately as a synopsis of the entire paper. It should not contain references to the bibliography. Manuscripts, in duplicate if possible, may be sent to any one of the four editors. Please classify according to the scheme of Math. Rev. 36, 1539-1546. All other communications to the editors should be addressed to the managing editor, Richard Arens, University of California, Los Angeles, California, 90024.

50 reprints are provided free for each article; additional copies may be obtained at cost in multiples of 50 .

The Pacific Journal of Mathematics is published monthly. Effective with Volume 16 the price per volume (3 numbers) is $\$ 8.00$; single issues, $\$ 3.00$. Special price for current issues to individual faculty members of supporting institutions and to individual members of the American Mathematical Society: $\$ 4.00$ per volume; single issues $\$ 1.50$. Back numbers are available.

Subscriptions, orders for back numbers, and changes of address should be sent to Pacific Journal of Mathematics, 103 Highland Boulevard, Berkeley, California, 94708.

PUBLISHED BY PACIFIC JOURNAL OF MATHEMATICS, A NON-PROFIT CORPORATION

Printed at Kokusai Bunken Insatsusha (International Academic Printing Co., Ltd.), 7-17, Fujimi 2-chome, Chiyoda-ku, Tokyo, Japan.

* Acting Managing Editor. 


\section{Pacific Journal of Mathematics}

\section{Vol. 32, No. 3 \\ March, 1970}

Shair Ahmad, Dynamical systems of characteristic $0^{+} \ldots \ldots \ldots \ldots \ldots$

Charles A. Akemann and Bernard Russo, Geometry of the unit sphere of a $C^{*}$-algebra and its dual............................ 575

Philip Bacon, The compactness of countably compact spaces ......... 587

Richard Blaine Barrar and Henry Loeb, On the continuity of the nonlinear Tschebyscheff operator ............................ 593

L. Carlitz, Factorization of a special polynomial over a finite field ....... 603

Joe Ebeling Cude, Compact integral domains .................... 615

Frank Rimi DeMeyer, On automorphisms of separable algebras. II . . . . . 621

James B. Derr, Generalized Sylow tower groups .................. 633

Raouf Doss, Some inclusions in multipliers ................... 643

Mary Rodriguez Embry, The numerical range of an operator........... 647

John Froese, Domain-perturbed problems for ordinary linear differential

operators..................................... 651

Zdeněk Frolík, Absolute Borel and Souslin sets ..................... 663

Ronald Owen Fulp, Tensor and torsion products of semigroups .......... 685

George Grätzer and J. Płonka, On the number of polynomials of an

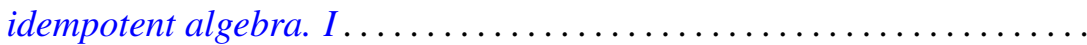

Newcomb Greenleaf and Walter Read, Positive holomorphic differentials on

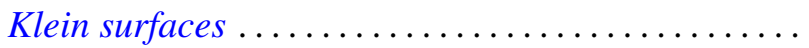

John Willard Heidel, Uniqueness, continuation, and nonoscillation for a second order nonlinear differential equation ................. 715

Leon A. Henkin, Extending Boolean operations................... 723

R. Hirshon, On hopfian groups .......................... 753

Melvin Hochster, Totally integrally closed rings and extremal spaces ..... 767

R. Mohanty and B. K. Ray, On the convergence of a trigonometric integral ..................................

Michael Rich, On a class of nodal algebras .................... 787

Emile B. Roth, Conjugate space representations of Banach spaces ........ 793

Rolf Schneider, On the projections of a convex polytope .............. 799

Bertram Manuel Schreiber, On the coset ring and strong Ditkin sets ...... 805

Edgar Lee Stout, Some remarks on varieties in polydiscs and bounded

holomorphic functions .........................

James Edward Ward, Two-groups and Jordan algebras . 